\title{
Association Between HLA DQB 1 * 03 and Cervical Intra-epithelial Neoplasia
}

\author{
Kunle Odunsi," George Terry, ${ }^{\dagger}$ Linda Ho, ${ }^{\dagger}$ John Bell, ${ }^{\ddagger}$ \\ Jack Cuzick, ${ }^{\mathbf{\$}}$ and Trivadi S. Ganesan* \\ *ICRF Molecular Oncology Laboratories, Institute of Molecular \\ Medicine, John Radcliffe Hospital, Oxford, United Kingdom \\ ${ }^{\dagger}$ Departments of Molecular Pathology and Medical Microbiology, \\ University College, London, United Kingdom \\ ${ }^{\ddagger}$ Nuffield Department of Medicine, John Radcliffe Hospital, Oxford, \\ United Kingdom \\ ${ }^{\S}$ Department of Mathematics, Statistics, and Epidemiology, Imperial \\ Cancer Research Fund, London, United Kingdom
}

\begin{abstract}
Background: Cervical intraepithelial neoplasia (CIN) and cervical cancer have been shown to be strongly associated with infection by human papillomavirus (HPV). However, other factors may be contributory in the progression from normal epithelium to CIN and cervical cancer, since not all women with HPV infection develop disease. Recently, it was demonstrated that there is a high risk for cervical cancer and CIN in women with HLA DQB1 * 03 ( $\mathrm{RR}=7.1, p<0.0009)$ (1). Subsequent reports have been conflicting, due to sample size, genetic heterogeneity and differences in the techniques employed for the detection of HLA $\mathrm{DQB1}$ * 03.

Materials and Methods: DNA from cervical smears of 178 women with CIN and 420 controls with normal cervical cytology was analyzed by polymerase chain reaction (PCR) with type-specific primers for HPV 16, 18,31 , and 33. The DNA from test and control samples were also analyzed by a novel PCR technique, which mutates the first base of codon 40 (DQ alleles) from $T$ to $\mathrm{G}$ to create an artificial restriction site for an enzyme $M l u$ I that distinguish $\mathrm{DQB} 1 * 03$ from other alleles and are confirmed by digestion of amplified DNA with
\end{abstract}

$M l u$ I. Further analysis of individual DQB 1 * 03 alleles was performed using PCR and allele-specific primers. Results: One hundred forty-four (34\%) out of 420 controls (all HPV 16, 18, 31, or 33 negative and normal cytology), 37/66 (56\%) of CIN I and 72/112 (64\%) of CIN III were positive for DQBl * 03 (trend test, $\left.p<0.001, \chi^{2}=37.3\right)$. A significant association was observed between DQBI * 03 and CIN (odds ratio 3.03; 95\% CI 2.11-3.45). Of women with CIN, 131/ $178(73.5 \%)$ had HPV (types 16, 18, 31, or 33) infection. There was a significant association between DQB1 * 03 and presence of HPV (odds ratio 3.43; 95\% CI 2.25-5.10). Homozygosity for DQB1 * 03 was more strongly associated with CIN than heterozygosity (odds ratios 4.0 and 2.63, respectively); and for the presence of HPV (odds ratio 4.47; 95\% CI 2.58-7.77). HLA $\mathrm{DQB1}$ * 0301 was the most strongly associated allele with CIN and HPV (odds ratios 2.53 and 2.63, respectively).

Conclusions: HLA DQB $* 03$ is associated significantly with CIN and may be permissive for HPV infection. Further analysis of class II HLA typing in CIN is necessary to evaluate this association.

\section{INTRODUCTION}

The hypothesis that human papillomavirus (HPV) is causally associated with cervical intra-

Address correspondence and reprint requests to: Dr. T. S. Ganesan, ICRF Molecular Oncology Laboratories, Institute of Molecular Medicine, John Radcliffe Hospital, Oxford OX3 9DU, United Kingdom. epithelial neoplasia (CIN) and cervical cancer is well supported by several lines of evidence. First, HPV is detected in the cervical tissue of majority of patients with disease, compared with controls $(2,3)$. Second, the oncogenic types of HPV can transform and immortalize human keratinocytes in vitro $(4,5)$. Third, the HPV16 $\mathrm{E}_{6}$ and $\mathrm{E}_{7}$ proteins inactivate endogenous tumour suppressor 
proteins $\mathrm{p} 53$ and $\mathrm{Rb}$, thereby abrogating normal cell control mechanisms (6). Despite this, the majority of women infected with HPV do not develop CIN or cancer. Several cofactors have been suggested as being important. A recent analysis of HLA type has shown a significant association between HLA class II, in particular HLA DQBI * 03, and cervical cancer but not for class I (1). Subsequent reports have not been consistent (Table 1) presumably due to the size and type of population examined and differences in techniques used for the HLA and HPV typing. As cervical intraepithelial neoplasia (CIN) is an early stage prior to the development of cervical cancer, any association with HLA class II that could be demonstrated would be important. This paper reports the results of such a study conducted in a Caucasian population, where both controls and test samples were typed for HPV and HLA DQB1 * 03.

\section{MATERIALS AND METHODS}

\section{Sample Collection}

Cervical smears were taken using standard procedures from healthy women and those with CIN attending the outpatient clinics at City Hospital, Nottingham; Whittington Hospital, London, and the Margaret Pyke center, London. Further processing of samples for PCR was performed as described $(7,8)$.

\section{Histological Diagnosis}

Histological classification into the three groups of normal, CIN I, and CIN III were carried out according to established criteria $(9,10)$.

\section{HPV Typing}

HPV typing by PCR was performed using type specific oligonucleotide primers (HPV 16, 18, 31, 33) as previously described. $(7,8)$

\section{HLA Typing}

A rapid system to type the HLA DQB 1 * 03 was developed using primer directed mutagenesis by PCR and restriction enzyme digestion (artificial restriction fragment lenth polymorphism [ARFLP]-PCR) (11). All DQB1 * 03 alleles possess an $A$ as the last base of codon 38 followed by CGC (codon 39) and TTC (codon 40) (Fig. 1). By mutating the first base of codon 40 , from " $\mathrm{T}$ " to "G", a Mlu I site (ACGCGT) is created in the $\mathrm{DQB1}$ * 03 allele. Non DQB 1 * 03 alleles possess a " $G$ " as the last base of codon 38 , and a $M l u$ I site cannot be created this way. The forward primer $A$ is used in conjunction with the reverse mutagenesis primer $\mathrm{B}$ :

\section{A: 5' AGGGATCCCCGCAGAGGATTTCGTGTACC 3'}

(forward)

B: 5' CCGGTACACCCCCACGTCGCTGTCGACGGC 3'

(reverse)

(The mutated base is underlined.) PCR was carried out as described in $50 \nu \mathrm{l}$ volume using a Techne-PC 3 machine, according to manufacturer's instructions. The initial denaturation was at $94^{\circ} \mathrm{C}$ for $8 \mathrm{~min}$ followed by 30 cycles each at $94^{\circ} \mathrm{C}$ for $1 \mathrm{~min}, 60^{\circ} \mathrm{C}$ for $1 \mathrm{~min}$, and $72^{\circ} \mathrm{C}$ for 1 min. There was a final extension step at $72^{\circ} \mathrm{C}$ for $15 \mathrm{~min}$.

Following amplification $10 \mu \mathrm{l}$ of the PCR product was restricted with 50 units of $M l u$ I (Boehringer Mannheim) in a volume of $20 \mu \mathrm{l}$ at $37^{\circ} \mathrm{C}$ overnight using manufacturer's buffer. The products were analyzed by electrophoresis on $4 \%$ agarose gels (Metaphor, Flowgen) (Fig. 2).

Further typing for HLA DQB1 * 03 for 0301 , 0302, 0303, and 0304 in samples that were positive for the HLA DQB1 * 03 phenotype was performed by PCR using a combination of sequence specific primers (12) (Table 2). The annealing temperature for all the primer pairs was $60^{\circ} \mathrm{C}$, and other PCR conditions were as published (12). All PCR reactions were performed with both positive and negative controls. The amplified products were separated by agarose gel electrophoresis and visualized by ultraviolet (UV) light.

\section{Statistical Analysis}

Odds ratios and their approximate $95 \%$ confidence intervals were calculated for all variables by a $\chi^{2}$ test for $2 \times 2$ tables without a continuity correction (13). For $2 \times \mathrm{k}$ tables the $\chi^{2}$ test for trend was calculated (14). The unit of sampling was the individual in all analysis except when studying specific alleles. In that case, each allele was taken as an independent observation so that the sample size was twice as large for allele specific comparisons. 


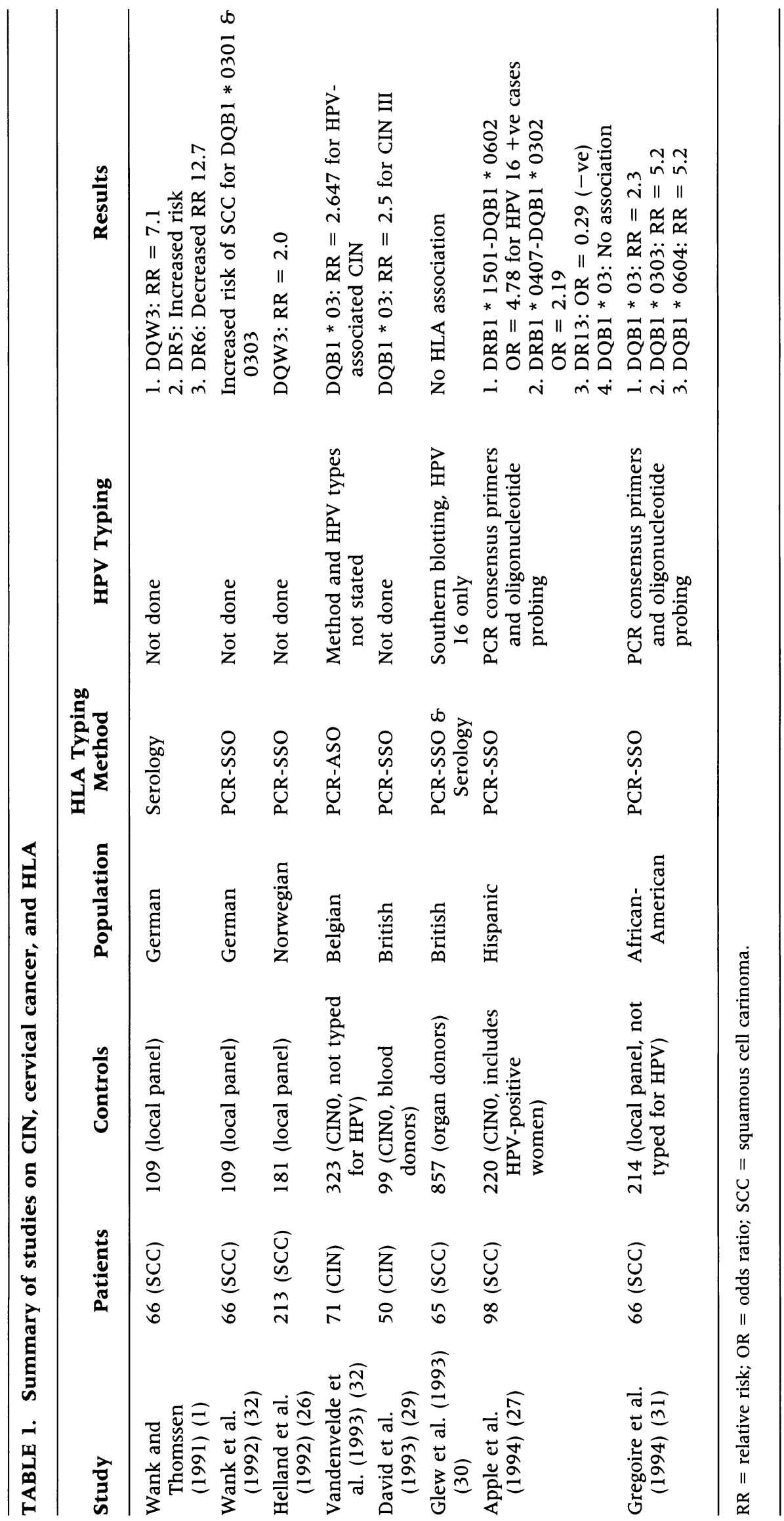




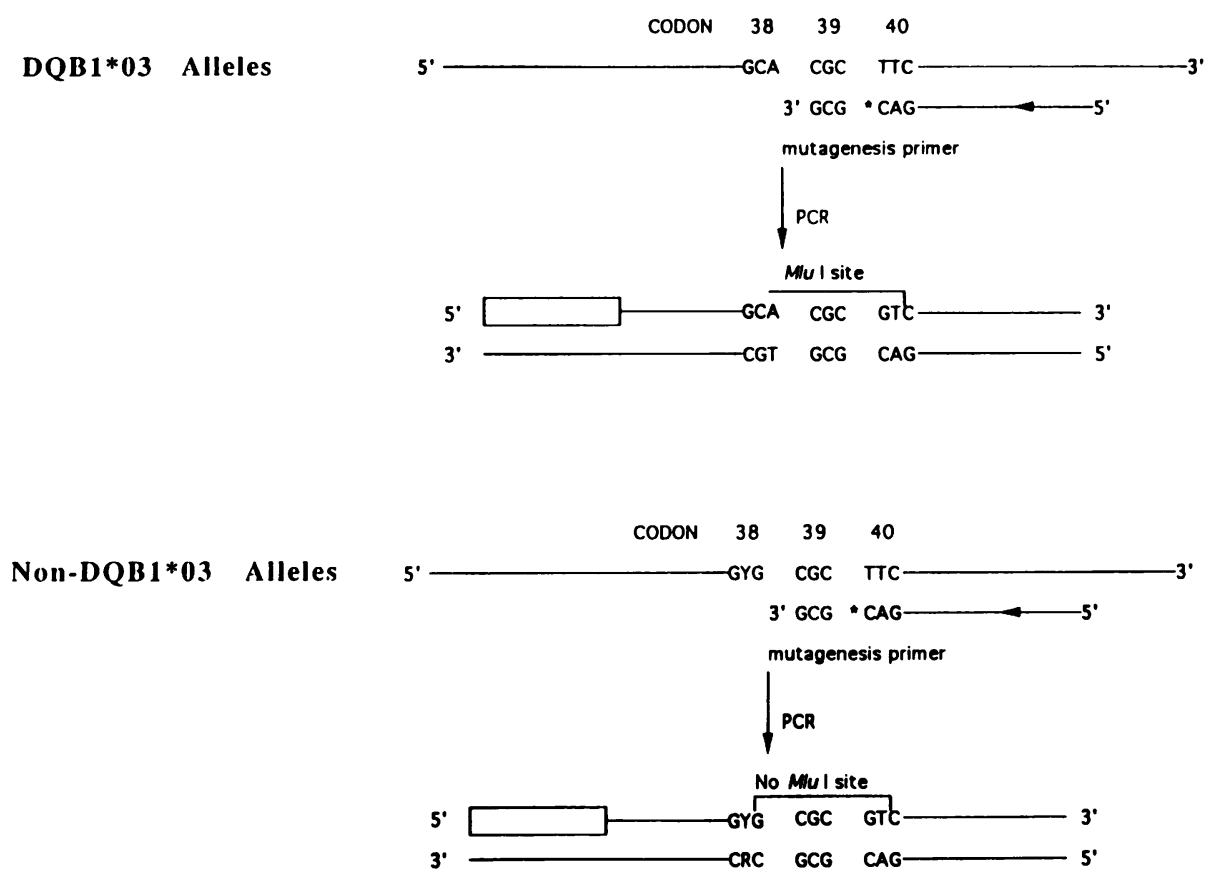

FIG. 1. A schematic diagram showing the principle of ARFLP-PCR

\section{RESULTS}

\section{Overall (Table 3)}

HLA DQB $1 * 03$ typing was performed on DNA from cervical smears of 178 women with CIN (CIN I $=66$; CIN III $=112)$ and 420 healthy women who had a normal smear. All samples were successfully amplified for the locus. HPV

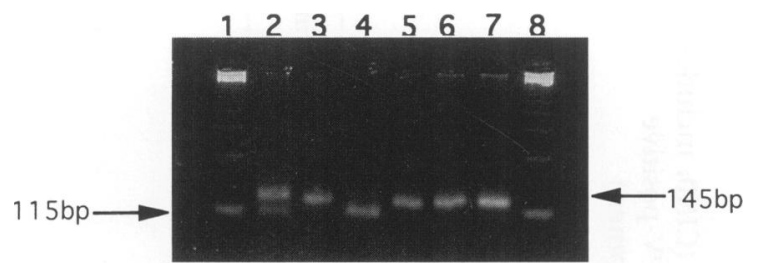

FIG. 2. A $4 \%$ agarose gel showing amplified DNA after PCR with primers $A$ and $B$ with and without digestion by Mlu I

The size of amplified DNA is 145 bp and on digestion with Mlu I, a 115 and $30 \mathrm{bp}$ product is produced in $\mathrm{DQB1}$ * 03 homozygotes. DNA for all controls were from the British Society for Histocompatibilty and Immunogenetics. Arrows show the 145 and 115 bp products. (Lanes 2 and 3) Heterozygous $\mathrm{DQB1}$ * 03 control with and without digestion by $M l u$ I. (Lanes 4 and 5) Homozygous DQBl * 03 control with and without digestion with $M l u$ I. (Lanes 6 and 7) Non-DQB1 * 03 control with and without digestion with $M l u$ I. (Lanes 1 and 8) 123 bp markers. typing was performed for types 16, 18, 31, and 33 on all the test and control samples.

Of CIN cases, $61 \%$ were positive $(56 \%$ of CIN $1,64 \%$ of CIN III) for the HLA DQB1 * 03 type, compared with $34 \%$ of controls. This was significant $\left(\chi^{2}\right.$ trend $\left.=37.3, p<0.001\right)$, and the odds ratio for CIN overall was 3.03 (95\% CI 2.11-4.35). The association was significant for both CIN III and CIN I (odds ratio 3.45 versus 2.45), stronger for CIN III, but not significantly different from CIN I.

One hundred thirty-one patients with CIN $(73.5 \%)$ were positive for one or more HPV types $16,18,31$, and 33. Of HPV-positive CIN, $64 \%$ were of the type DQB1 * 03 . There was a significant association between DQB1 * 03 and HPV $\left(\chi^{2}\right.$ trend $\left.=23.2, p<0.001\right)$ with an odds ratio of 3.43 (95\% CI $2.28-5.15)$.

\section{Association Between HLA DQB 1 * 03 and CIN (Tables 4 and 5).}

The ARFLP-PCR technique used on DNA from cervical smears, following $M l u$ I digestion, identifies women who are negative, heterozygous, or homozygous for the DQB1 * 03 locus (Fig. 2). Of women with $\mathrm{CIN}, 38 \%$ were negative, $37 \%$ were heterozygous, and $23 \%$ were homozygous for the $\mathrm{DQBl} * 03$ locus $\left(\chi^{2}\right.$ trend $=39.01$, $p<0.001)$. Compared with controls, the odds 
TABLE 2. Sequence-specific primer pairs for typing the HLA DQB1 * 03 locus

\begin{tabular}{|c|c|c|}
\hline HLA Allele & $\begin{array}{c}\text { Primer Sequences } \\
\text { FAMP/RAMP }\end{array}$ & $\begin{array}{c}\text { Size/PCR } \\
\text { Product (bp) }\end{array}$ \\
\hline \multirow[t]{2}{*}{$\mathrm{DQB} 1 * 0201$} & 5' GTGCGTCTTGTGAGCAGAAG 3' & 205 \\
\hline & 5' GCAAGGTCGTGCCGAGCT 3' & \\
\hline \multirow[t]{2}{*}{$\mathrm{DQB1} * 0201 / 0302$} & 5' GACGGAGCGCGTGCGTCT 3' & 129 \\
\hline & 5' CTGTTCCAGTACTCGGCGG 3' & \\
\hline \multirow[t]{2}{*}{$\mathrm{DQB} 1 * 0301 / 0304$} & 5' GACGGAGCGCGTGCGTTA 3' & 122 \\
\hline & 5' AGTACTCGGCGTCAGGCG $3^{\prime}$ & \\
\hline \multirow[t]{2}{*}{$\mathrm{DQB} 1 * 0302 / 0303$} & 5' GACGGAGCGCGTGCGTTA 3' & 122 \\
\hline & 5' AGTACTCGGCGTCAGGCG $3^{\prime}$ & \\
\hline \multirow[t]{2}{*}{$\mathrm{DQB} 1 * 0303$} & 5' GACGGAGCGCGTGCGTTA $3^{\prime}$ & 129 \\
\hline & 5' CTGTTCCAGTACTCGCGT 3' & \\
\hline \multirow[t]{2}{*}{$\mathrm{DQB} 1 * 0601$} & 5' GCCATGTGCTACTTCACCAAT 3' & 198 \\
\hline & 5' CACCGTGTCCAACTCCGCT 3' & \\
\hline \multirow[t]{2}{*}{$\mathrm{DQB} 1 * 0601 / 0301$} & 5' GACGGAGCGCGTGCGTTA 3' & 129 \\
\hline & 5' CTGTTCCAGTACTCGGCGT $3^{\prime}$ & \\
\hline \multirow[t]{2}{*}{$\mathrm{DQB} 1 * 0304$} & 5' GACGGAGCGCGTGCGTTA 3' & 129 \\
\hline & 5' CTGTTCCAGTACTCGGCGG $3^{\prime}$ & \\
\hline
\end{tabular}

FAMP Forward amplification primer; RAMP reverse amplification primer.

ratio was greater for homozygosity $(4.0,95 \% \mathrm{CI}$ $2.43-6.6)$ than for heterozygosity $(2.63,95 \% \mathrm{CI}$ 1.75-3.94). Further typing of the DQBl * 03 locus in positive samples showed that the 0301

TABLE 3. Summary of distribution of HLA DQB 1 * 03

\begin{tabular}{|c|c|c|}
\hline Patients (No.) & $\begin{array}{c}\text { HLA DQB I * } 03 \\
\text { (Positive) (\%) }\end{array}$ & $\begin{array}{l}\text { Odds Ratio } \\
\text { (95\% CI) }\end{array}$ \\
\hline CIN (178) & $109(61)$ & $3.03(2.11-4.35)$ \\
\hline CIN l (66) & $37(56)$ & $2.45(1.45-4.12)$ \\
\hline CIN 3 (112) & $72(64)$ & $3.45(2.23-5.33)$ \\
\hline $\begin{array}{l}\text { HPV negative } \\
\text { CIN (47) }\end{array}$ & $25(53)$ & $2.18(1.19-3.97)$ \\
\hline $\begin{array}{l}\text { HPV positive } \\
\text { CIN (131) }\end{array}$ & $84(64)$ & $3.43(2.28-5.15)$ \\
\hline $\begin{array}{l}\text { Controls (420) } \\
\text { (HPV negative }\end{array}$ & $144(34)$ & $1 *$ \\
\hline \multicolumn{3}{|c|}{$\begin{array}{l}{ }^{*} \text { Reference category. } \\
\chi^{2} \text { trend for controls, CIN } 1 \text {, and CIN } 3=37.3, p<0.001 \text {. } \\
\chi^{2} \text { trend for controls, HPV negative, and HPV positive }= \\
38.6, p<0.001\end{array}$} \\
\hline
\end{tabular}

allele was present in $40 \%$ of CIN as opposed to $9 \%$ of controls (odds ratio $2.53,95 \%$ CI $1.79-$ 3.57; $\chi^{2}$ trend $\left.=28.6, p<0.001\right)$. DQB1 * 0302 was present in $32 \%$ and $10 \%$ of CIN and controls, respectively (odds ratio $1.84,95 \%$ CI $1.29-$ 2.62).

\section{Association Between HPV and HLA DQB 1 * 03 (Tables 6, 7, and 8).}

HPV typing was performed for the major oncogenic types, HPV 16, 18, 31, and 33. Of CIN cases, $57 \%$ were positive for HPV $16,7 \%$ for HPV 18 , $12 \%$ for HPV 31 , and $7 \%$ for HPV 33 , and $16 \%$ were positive for multiple types. All types correlated strongly with $\mathrm{DQBl} * 03$, but there was insufficient data to find differences in the strength of association between the types. The highest odds ratio was found for women with HPV 18 or multiple types. There was significant correlation with "gene dosage" at the DQBI * 03 locus, with $39 \%$ of HPV-positive CIN being heterozygous and $24 \%$ homozygous $\left(\chi^{2}\right.$ trend $=$ $37.9, p<0.001)$. Homozygosity was significantly associated with HPV-positive CIN (odds ratio $4.47,95 \%$ CI $2.58-7.77$ ). Further typing of the HLA DQB 1 *03 locus in positive samples 
TABLE 4. Association between HLA DQBI * 03 and CIN

\begin{tabular}{lccc}
\hline HLA & $\begin{array}{c}\text { Controls } \\
(\%)\end{array}$ & $\begin{array}{c}\text { CIN } \\
(\%)\end{array}$ & $\begin{array}{c}\text { Odds Ratio } \\
\text { (95\% CI) }\end{array}$ \\
\hline $\begin{array}{l}\text { Non-DQB1 *03 } \\
\text { Heterozygous for } \\
\text { DQB 1 *03 }\end{array}$ & $276(65)$ & $69(38)$ & $1^{*}$ \\
$\begin{array}{l}\text { Homozygous for } \\
\text { DQB 1 * 03 }\end{array}$ & $102(24)$ & $67(37)$ & $2.63(1.75-3.94)$ \\
\begin{tabular}{l} 
Total \\
\hline
\end{tabular} & $42(10)$ & $42(23)$ & $4.0(2.43-6.60)$ \\
\hline
\end{tabular}

* Reference category.

$\chi^{2}$ trend $=39.01, p<0.001$.

showed that the 0301 allele was most strongly associated with HPV infection (odds ratio 2.69, 95\% CI 1.88-3.94; $\chi^{2}$ trend $\left.=32.9, p<0.001\right)$.

\section{DISCUSSION}

Cancer of the uterine cervix is the second most common cancer world-wide and the most common cancer in developing countries (15). The annual incidence in the UK is 4,000 cases per year, with 2,000 dying as a result of the disease. Cervical intraepithelial neoplasia which precedes cervical cancer is even more common. Both cer- vical cancer and CIN have been shown to be strongly associated with the oncogenic types of the human papillomaviruses (types 16, 18, 31, $33,35,39,45,51,52,56$, and 58) (16,17). An overview of studies show that the incidence of HPV infection detected by PCR based techniques in women with normal cervical cytology varies from $6-53 \%(18)$. There also exists a long latency period between HPV infection and cervical cancer (19). Therefore, additional factors are probably involved in the transformation of normal epithelium to CIN and cervical cancer after HPV infection. One such factor is possibly immunological, as in other virus induced cancers, such

\section{TABLE 5. Association between HLA DQBI * 03 allele and CIN}

\begin{tabular}{|c|c|c|c|c|c|}
\hline $\begin{array}{l}\text { HLA } \\
\text { DQB1 * } 03 \\
\text { Allele }\end{array}$ & $\begin{array}{c}\text { CIN 3 } \\
(2 n=224)\end{array}$ & $\begin{array}{c}\text { CIN 1 } \\
(2 n=132)\end{array}$ & $\begin{array}{c}\text { Controls } \\
(2 n=840)\end{array}$ & $\begin{array}{c}\text { Odds Ratio } \\
\text { (95\% CI) }\end{array}$ & $\stackrel{x^{2}}{\text { Trend }}$ \\
\hline 0301 & $49(21)$ & $25(19)$ & $79(9)$ & $2.53(1.79-3.57)$ & $\begin{array}{c}28.6 \\
(p<0.001)\end{array}$ \\
\hline 0302 & $45(20)$ & $16(12)$ & $85(10)$ & $1.84(1.29-2.62)$ & $\begin{array}{c}15.5 \\
(p<0.001)\end{array}$ \\
\hline 0303 & $5(2)$ & $7(5)$ & $21(2.5)$ & $1.36(0.67-2.76)$ & $\begin{array}{c}0.05 \\
(p=0.82)\end{array}$ \\
\hline 0304 & 0 & 0 & $1(0.1)$ & 0 & \\
\hline Non-DQB $1 * 03$ & 125 & 84 & 654 & $1^{*}$ & \\
\hline Total & 224 & 132 & 840 & & \\
\hline
\end{tabular}

* Reference category. 
TABLE 6. Association between HLA DQB1 * 03 and HPV type

\begin{tabular}{lccc}
\hline $\begin{array}{l}\text { HPV Type } \\
\text { Present }\end{array}$ & $\begin{array}{c}\text { Number of } \\
\text { Patients }\end{array}$ & $\begin{array}{c}\text { DQB1 * 03 } \\
\text { (Positive) } \\
\text { (\%) }\end{array}$ & $\begin{array}{c}\text { Odds Ratio } \\
\text { (95\% CI) }\end{array}$ \\
\hline 16 & 75 & $45(60)$ & $2.88(1.74-4.74)$ \\
18 & 9 & $7(77)$ & $6.71(1.56-\infty)$ \\
31 & 16 & $11(68)$ & $4.22(1.5-11.84)$ \\
33 & 10 & $6(60)$ & $2.88(0.86-9.64)$ \\
Multiple types & 21 & $15(71)$ & $4.79(1.88-12.2)$ \\
Controls & 420 & $144(34)$ & $1 *$ \\
(HPV negative) & & & \\
\hline
\end{tabular}

* Reference category.

as nasopharyngeal carcinoma due to EpsteinBarr virus (20). In immunocompromised women following renal transplantation, the risk for cervical cancer is increased 10 fold (21). HIV infected patients also show an increased frequency of CIN (22). Analysis of HLA class I and II antigens in cervical cancer has shown that loss of class I expression occurs in a third of patients, while the majority demonstrated increased class II expression $(23,24)$.

HLA type has been analyzed by several groups in patients with cervical cancer and CIN with different conclusions (Table 1). The discrepancy in the results between different investigators maybe due to several reasons. Serological typing of DQB 1, as in the initial report, is prone to significant error (25). The sample size was adequate in only two studies $(26,27)$. In fact, analysis on a sufficiently large number of cases of CIN has not been performed, though two preliminary studies reported that the DQB $1 * 03$ locus was associated significantly with CIN (Table 1) $(28,29)$. The controls in several studies were from local donor panels and not necessarily comparable. Typing for HPV was performed in only three studies $(27,30,31)$. To address these issues we have performed a larger study with sufficient number of cases and controls to evaluate the significance of DQBI * $\mathrm{O} 3$ association with cervical intraepithelial neoplasia. Further, it is quite important to evaluate the association between CIN, HPV, and DQB 1 * 03 using controls that are negative for HPV and have a normal cytology.

The typing for HLA DQBl * 03 was performed with a rapid technique which was concordant with data based on sequencing (11). This

TABLE 7. Association between HLA DQBI * 03 and HPV

\begin{tabular}{lccr}
\hline HLA & $\begin{array}{c}\text { Controls } \\
(\%)\end{array}$ & $\begin{array}{c}\text { HPV Positive } \\
\text { CIN (\%) }\end{array}$ & $\begin{array}{c}\text { Odds Ratio } \\
\text { (95\% CI) }\end{array}$ \\
\hline $\begin{array}{l}\text { Non-DQB1 *03 } \\
\begin{array}{l}\text { Heterozygous for } \\
\text { DQB 1 * 03 }\end{array}\end{array}$ & $276(65 \%)$ & $47(35 \%)$ & $1 *$ \\
$\begin{array}{l}\text { Homozygous for } \\
\text { DQB 1 * 03 }\end{array}$ & $102(24 \%)$ & $52(39 \%)$ & $2.99(1.90-4.71)$ \\
\begin{tabular}{l} 
Total \\
\hline
\end{tabular} & $42(10 \%)$ & $32(24 \%)$ & $4.47(2.58-7.77)$ \\
\hline
\end{tabular}

* Reference category.

$\chi^{2}$ trend $=37.9, p<0.001$. 
TABLE 8. Association between HLA DQB1 * 03 allele and HPV

\begin{tabular}{|c|c|c|c|c|c|}
\hline $\begin{array}{l}\text { HLA } \\
\text { DQB1 * } 03 \\
\text { Allele }\end{array}$ & $\begin{array}{c}\text { CIN HPV } \\
\text { (Positive) } \\
(2 n=262) \\
(\%)\end{array}$ & $\begin{array}{c}\text { CIN HPV } \\
\text { (Negative) } \\
(2 n=94) \\
(\%)\end{array}$ & $\begin{array}{c}\text { Controls } \\
\text { HPV } \\
\text { (Negative) } \\
(2 n=840) \\
(\%)\end{array}$ & $\begin{array}{c}\text { Odds Ratio } \\
\text { (95\% CI) }\end{array}$ & $\underset{\text { Trend }}{\chi^{2}}$ \\
\hline 0301 & $60(22)$ & $14(15)$ & $79(9)$ & $2.69(1.88-3.94)$ & $\begin{array}{l}32.9 \\
(p<0.001)\end{array}$ \\
\hline 0302 & $45(17)$ & $16(17)$ & $85(10)$ & $1.71(1.17-2.50)$ & $\begin{array}{l}10.6 \\
(p<0.001)\end{array}$ \\
\hline 0303 & $9(3)$ & $3(3)$ & $21(2.5)$ & $1.35(0.63-2.89)$ & $\begin{array}{l}0.71 \\
(p<0.4)\end{array}$ \\
\hline 0304 & 0 & 0 & $1(0.1)$ & 0 & \\
\hline Non-DQB $1 * 03$ & $148(56)$ & $61(65)$ & $654(78)$ & $1^{*}$ & \\
\hline Total & 262 & 94 & 840 & & \\
\hline
\end{tabular}

* Reference category.

technique is also informative in assessing whether the individual sample is heterozygous or homozygous for the DQB1 * 03 locus. The results show a significant association between CIN and DQBI * 03 which is only slightly stronger for CIN III than CIN I. The association between CIN and DQB 1 * 03 that we found (odds ratio 3.03) was weaker than that reported by Wank and Thomssen (1). A slightly stronger association in HPV-positive CIN (odds ratio 3.43) was observed than that reported by Van den velde et al. (28). Homozygosity at the DQB1 * 03 locus, was significantly associated (odds ratio 4.0) with CIN and was more strongly related than heterozygosity, a result not reported so far in any of the previous studies. The 0301 allele was the most strongly associated with CIN (odds ratio $2.53, \chi^{2}=28.6, p<0.001$ ), but 0302 was also positively related. This agrees with Wank and Thomssen's DNA typing data for 0301 on their original sample of cervical cancer patients (32). A significant association with HPV-positive CIN and DQB 1 * 03 was found for all HPV types tested (types 16, 18, 31, and 33). Again, homozygosity at the DQB1 * 03 locus was strongly associated with HPV-positive CIN (odds ratio 4.47) with intermediate risk found for heterozygotes. Typing for HPV has not always been performed in all the previous studies, but in general HPVpositive CIN was significantly associated with the
DQB 1 * 03 phenotype. In our study, only the most prevalent oncogenic types have been determined, and it is possible that some of the HPVnegative CIN cases are positive for other types. Additional typing for other HPV types would probably increase the strength of the association. These results suggest that the DQB1 * 03 locus is probably an important determinant in allowing HPV infection to be tolerated and increasing the risk for high grade CIN or cancer.

Another disease due to HPV infection, recurrent respiratory papillomatosis, has been shown to be associated with the DQBI * 03 phenotype (33). In a preliminary analysis of 16 patients, $75 \%$ were positive for $\mathrm{DQB1} * 03$. Analysis of HLA class I and II using restriction fragment length polymorphism's in New Zealand rabbits infected with Shopecotton-tail rabbit papillomavirus showed a strong linkage between wart regression and DR locus, and an increased risk of malignant transformation with the DQ locus (34). Thus, based on our study and others, the DQB 1 * 03 locus seems to be important for HPV associated disease. The results of the analysis of HLA DR and DQ in squamous cell carcinoma reported by Apple et al. (27) in an Hispanic population are intriguing in that no significant association was found with the DQB ${ }^{*} 03$ locus, although the haplotype DRB ${ }^{*}$ 0407-DQB ${ }^{*} 0302$ was associated with increased risk of cervical car- 
cinoma. It may be partly related to ethnicity of the population under study.

There are at least three possible ways by which the association between DQB1 * 03 and HPV positive disease can be explained. These women may present peptide antigen to $\mathrm{CD} 4+\mathrm{T}$ cells ineffectively; clonal deletion of antigen specific $\mathrm{T}$ cell during thymic maturation may occur; or there maybe active suppression of immune response to HPV in DQB1 * 03 positive women. Although Mellins et al. (35) using T cell lines and specific HLA DP, DQ, and DR deletion mutants have shown that $20-30 \%$ of response to various recall antigens is restricted to $D Q$, in general, there is a bias against HLA-DQ restriction in human $\mathrm{T}$ cell clones reflecting a low level of expression of DQ on antigen presenting cells in the periphery (36). One proposal, in view of the above result, is that DQ is important in thymic selection of $\mathrm{T}$ cells. Indeed, there is a high level of expression of HLA DQ in the thymic cortex (37), and a role for negative selection for HPV-specific $\mathrm{T}$ cell clones would fit predisposition to HPVpositive CIN by the DQB 1 * 03 alleles. The other possible mechanism is based on observations of HLA-associated immunological low responsiveness to antigens such as streptococcal cell wall (38), schistosoma (39), mycobaterium leprae (40), tetanus toxoid (41), and hepatitis surface antigen (42) either after natural exposure or after vaccination. Despite the controversy regarding the function of suppressor $\mathrm{T}$ cells, there is evidence to suggest that HLA DQ maybe the preferred restriction element for immunological suppression mediated by CD8-positive T suppressor cells $(43,44)$. It is possible that women who are positive for the $\mathrm{DQBl}{ }^{*} 03$ phenotype are unable to mount an effective cytotoxic $\mathrm{T}$ cell response against HPV infection. This is particularly important as it has been shown that HPV16 $\mathrm{E}_{7}$ is a target for cytotoxic $\mathrm{T}$ cells and can mediate tumor rejection (45).

The present study on CIN lays the framework for a more detailed study of DR and DQ in CIN to identify the significant haplotype. It is obvious that detailed investigation of mechanisms of HLA association with CIN would be important in improving the understanding of the biology of cervical cancer and generally be informative about virus associated cancer. This has obvious importance in the design of vaccines for prevention and treatment of HPV infection and associated disease.

\section{ACKNOWLEDGMENTS}

Acknowledgements to Dr. A. Hollingworth, Dr. A. Szarewski, and Prof. A. Singer for samples, and Dr. M. Anderson and Dr. A. M. Hanby for histological diagnosis, and Dr. R. Edwards for statistical analysis. Supported by the Imperial Cancer Research Fund and Wellbeing.

\section{REFERENCES}

1. Wank R, Thomssen C. (1991) High risk of squamous cell carcinoma of the cervix for women with HLA-DQw3. Nature 352: 723725.

2. Meijer CJLM, van den Brule AJC, Snijders PJF, Helmerhorst T, Kenemans P, Walboomers JMM. (1992) Detection of human papillomavirus in cervical scrapes by the polymerase chain reaction in relation to cytology: Possible implications for cervical cancer screening. In: Munoz N, Bosch FX, Shah KV, Meheus A (eds). The Epidemiology of Human Papillomavirus and Cervical Cancer. Oxford University Press, Oxford.

3. Lorincz AT, Reid R, Jenson B, Greenberg MD, Lancaster W, Kurman RJ. (1992) Human papillomavirus infection of the cervix: relative risk association of 15 common anogenital types. Obstet. Gynecol. 79: 328-337.

4. Hawley-Nelson P, Vousden KH, Hubbert NL, Lowy DR, Schiller JT. (1989) HPV16 E6 and E7 proteins cooperate to immortalize human foreskin keratinocytes. E.M.B.O. J. 8: 39053910.

5. Munger K, Phelps WC, Bubb V, Howley PM, Schlegel RM. (1989) The E6 and E7 genes of human papillomavirus type 16 together are necessary and sufficient for transformation of primary human keratinocytes. J. Virol. 63: 4417-4421.

6. Vousden KH. (1993) Interactions of human papillomavirus transforming proteins with the products of tumour suppresor genes. F.A.S.E.B. J. 7: 872-879.

7. Cuzick J, Terry G, Ho L, Hollingworth T, Anderson M. (1992) Human papillomavirus type 16 DNA in cervical smears as a predictor of high-grade cervical intraepithelial neoplasia. Lancet 339: 959-960.

8. Cuzick J, Terry G, Ho L, Hollingworth T, Anderson M. (1994) Type-specific human papillomavirus DNA in abnormal smears as a 
predictor of high-grade cervical intraepithelial neoplasia. Br. J. Cancer 69: 167-171.

9. Richart RM. (1987) Causes and management of cervical intraepithelial neoplasia. Cancer 60: 1951-1959.

10. Anderson $\mathrm{M}$, Brown C, Buckley $\mathrm{C}$, et al. (1991) Current views on cervical intraepithelial neoplasia. J. Clin. Pathol. 44: 969-978.

11. Mehal WZ, Lo YD, Herrington S, et al. (in press) Human papillomavirus infection plays an important role in determining the HLA associated risk of cervical carcinogenesis. $J$. Clin. Pathol.

12. Olerup O, Aldener A, Fogdell A. (1993) HLA-DQB 1 and -DQAl typing by PCR amplification with sequence-specific primers (PCR-SSP) in 2 hours. Tissue Antigens 41: 119-134.

13. Davis W, Breslow NE Day NE (eds). (1980) Statistical Methods in Cancer Research: vol.1: The analysis of case control studies. International Agency for Research on Cancer, Lyon.

14. Armitage P (ed). (1971) Statistical Methods in Medical Research. Blackwell, Oxford.

15. Parkin DM, Laara E, Muir CS. (1988) Estimates of the worldwide frequency of sixteen major cancers in 1980. Int. J. Cancer 41: 184197.

16. Schiffman $\mathrm{MH}$, Bauer HM, Hoover RN, et al. (1993) Epidemiologic evidence showing that human papillomavirus infection causes most cervical intraepithelial neoplasia. J. Natl. Cancer Inst. 85: 958-964.

17. Walboomers J, Melkert P, van den Brule A, Snijders P, Meijer C. (1992) The polymerase chain reaction for screening in diagnostic cytopathology of the cervix. In: Herrington CS, McGee JO (eds). Diagnostic Molecular Pathology. IRL press, Oxford.

18. Schneider A, Koutsky L. (1992) Natural history and epidemiological features of genital HPV infection. In: Munoz M, Bosch FX, Shah KV, Meheus A (eds). The Epidemiology of Cervical Cancer and Human Papillomavirus. International Agency for Research on Cancer, Lyon.

19. Zur Hausen H. (1986) Intracellular surveillance of persisting viral infections. Lancet $\mathbf{1}$ : 489-491.

20. Zur Hausen H. (1991) Viruses in human cancers. Science 254: 1167-1173.

21. Sillman FH, Sedlis A. (1987) Anogenital papillomavirus infection and neoplasia in immunodeficient women. In: Reed R (ed). $\mathrm{Hu}$ - man Papillomavirus. W. B. Saunders, Philadelphia.

22. Schafer A, Friemann W, Mielke M, Schwatlander B, Koch MA. (1991) The increased frequency of cervical dysplasia in women infected with the human immunodeficiency virus is related to the degree of immunosuppression. Am. J. Obstet. Gynecol. 164: 593599.

23. Connor MF, Stern PL. (1990) Loss of MHC class I expression in cervical carcinomas. Int. J. Cancer 46: 1029-1034.

24. Glew SS, Duggan-Keen M, Cabrera T, Stern PL. (1992) HLA class II antigen expression in human papillomavirus-associated cervical cancer. Cancer Res. 52: 4009-4016.

25. Mytilineos J, Scherer S, Opelz G. (1990) Comparison of RFLP-DR-Beta and serological HLA-DR typing in 1500 individuals. Transplantation 50: 870-873.

26. Helland A, Borresen AL, Kaern J, Ronningen KS, Thorsby E. (1992) HLA antigens and cervical carcinoma. Nature 356: 23.

27. Apple RJ, Erlich HA, Klitz W, Manos MM, Becker TM, Wheeler CM. (1992) HLA DR-DQ associations with cervical carcinoma show papilloma virus-type specificity. Nature Gen. 6: 157-162.

28. Vandenvelde $C$, deFoor $M$, vanBeers $D$. (1993) HLA-DQBl $* 03$ and cervical intraepithelial neoplasia grades I-III. Lancet 341: 442-444.

29. David ALM, Taylor GM, Gokhale D, Aplin JD, Seif MW, Tindall VR. (1992) HLADQBI $* 03$ and cervical intraepithelial neoplasia type III. Lancet 340: 52.

30. Glew SS, Duggan-Keen M, Ghosh AK, et al. (1993) Lack of association of HLA polymorphisms with human papillomavirus-related cervical cancer. Hum. Immunol. 37: 157-164.

31. Gregoire L, Lawrence WD, Kukuruga D, Eisenbrey AB, Lancester WD. (1994) Association between HLA-DQBl alleles and risk for cervical cancer in African-American women. Int. J. Cancer 57: 504-507.

32. Wank R, Meulen JT, Luande J, Eberhardt H-C, Pawlita M. (1993) Cervical intraepithelial neoplasia, cervical carcinoma, and risk for patients with HLA-DQB1 *0602, *301, *0303 alleles. Lancet 341: 1215.

33. Bonagura VR, O'Reilly ME, Abramson AL, Steinberg BM. (1993) Recurrent respiratory papillomatosis (RRP): Enriched HLA DQw3 phenotype and decreased class I MHC ex- 
pression. Proceedings of the 12th International Papillomavirus Conference. p. 48.

34. Han R, Breitburd F, Marche PN, Orth G. (1992) Linkage of regression and malignant conversion of rabbit viral papillomas to MHC class II genes. Nature 356: 66-68.

35. Mellins E, Woefel M, Pious D. (1987) Importance of HLA-DQ and HLA-DP restriction elements in T-cell responses to soluble antigens-Mutational analysis. Hum. Immunol. 18: $211-213$.

36. Altman DM, Sansom D, Marsh SGE. (1991) What is the basis for HLA-DQ associations with autoimmune disease? Immunol. Today 12: $267-270$.

37. Ishikura H, Ishikawa N, Aizawa M. (1987) Differential expression of HLA class II antigens in the human thymus-relative paucity of HLA-DQ antigens in the thymic medulla. Transplantation 44: 314-317.

38. Nishimura Y, Sasazuki T. (1983) Suppressor $\mathrm{T}$ cells control the HLA-linked low responsiveness to streptococcal antigen in man. $\mathrm{Na}$ ture 301: 67.

39. Sasazuki T, Ohta N, Kaneoka R, Kojima S. (1980) Association between an HLA haplotype and low responsiveness to schistosomal worm antigen in man. J. Exp. Med. 152: 314. 40. Ottenhoff THM, Walford C, Nishimura $\mathrm{Y}$,
Reddy NBB, Sasazuki T. (1990) HLA DQ molecules and the control of mycobaterium leprae specific $\mathrm{T}$ cell non responsiveness in lepromatous leprosy patients. Eur. J. Immunol. 20: 2347.

41. Sasazuki T, Kohno Y, Iwamoto I, Tanimura M, Naito S. (1978) Association between an HLA haplotype and low responsiveness to tetanus toxoid in man. Nature 272: 359.

42. Hatae K, Kimura A, Okubo R, et al. (1992) Genetic control of non responsiveness to hepatitis $B$ virus vaccine by an extended HLA haplotype. Eur. J. Immunol. 22: 18991905.

43. Salgame P, Convit J, Bloom BR. (1991) Immunological suppression by human $\mathrm{CD} 8+\mathrm{T}$ cells is receptor dependent and HLA-DQ restricted. Proc. Natl. Acad. Sci. U.S.A. 88: 25982602.

44. Sasazuki T, Kikuchi K, Hirayama $S$, Matsushita S, Ohta N, Nishimura Y. (1989) HLA-linked immune suppression in humans. Immunology S2: 21-25.

45. Chen L, Thomas EK, Hu SL, Hellstrom J, Hellstrom KE. (1991) Human papillomavirus type 16 nucleoprotein E7 is a tumour rejection antigen. Proc. Natl. Acad. Sci. U.S.A. 88: $110-114$.

Contributed by D. J. Weatherall on September 29, 1994. 